\title{
Expression profiling of ion channel genes predicts clinical outcome in breast cancer
}

\author{
Jae-Hong Ko ${ }^{1}$, Eun A Ko ${ }^{2}$, Wanjun Gu${ }^{3}$, Inja Lim', Hyoweon Bang ${ }^{1 *}$ and Tong Zhou ${ }^{4,5^{*}}$
}

\begin{abstract}
Background: Ion channels play a critical role in a wide variety of biological processes, including the development of human cancer. However, the overall impact of ion channels on tumorigenicity in breast cancer remains controversial.

Methods: We conduct microarray meta-analysis on 280 ion channel genes. We identify candidate ion channels that are implicated in breast cancer based on gene expression profiling. We test the relationship between the expression of ion channel genes and p53 mutation status, ER status, and histological tumor grade in the discovery cohort. A molecular signature consisting of ion channel genes (IC30) is identified by Spearman's rank correlation test conducted between tumor grade and gene expression. A risk scoring system is developed based on IC 30 . We test the prognostic power of IC30 in the discovery and seven validation cohorts by both Cox proportional hazard regression and log-rank test.
\end{abstract}

Results: 22, 24, and 30 ion channel genes are found to be differentially expressed with a change in p53 mutation status, ER status, and tumor histological grade in the discovery cohort. We assign the 30 tumor grade associated ion channel genes as the IC30 gene signature. We find that IC30 risk score predicts clinical outcome $(P<0.05)$ in the discovery cohort and 6 out of 7 validation cohorts. Multivariate and univariate tests conducted in two validation cohorts indicate that IC30 is a robust prognostic biomarker, which is independent of standard clinical and pathological prognostic factors including patient age, lymph node status, tumor size, tumor grade, estrogen and progesterone receptor status, and p53 mutation status.

Conclusions: We identified a molecular gene signature IC30, which represents a promising diagnostic and prognostic biomarker in breast cancer. Our results indicate that information regarding the expression of ion channels in tumor pathology could provide new targets for therapy in human cancers.

Keywords: Ion channel, Breast cancer, Gene expression, p53, Estrogen receptor, Molecular signature, Microarray

\section{Background}

Ion channels are membrane proteins expressed in various tissues that allow the passage of ions across biological membranes. Ion transport is a key component in a wide variety of biological processes including electrical impulse generation and conduction along nerves, fluid balancing within cells and across cell membranes, and signal transduction within and among cells. In addition, ion channels are known to play critical roles in gene expression, hormone secretion, muscle contraction,

\footnotetext{
* Correspondence: haena@cau.ac.kr; tongzhou@uic.edu

'Department of Physiology, College of Medicine, Chung-Ang University, Seoul 156-756, South Korea

${ }^{4}$ Institute for Personalized Respiratory Medicine, University of Illinois at Chicago, Chicago, IL 60612, USA

Full list of author information is available at the end of the article
}

immune response, cell volume regulation, and cell proliferation [1-7]. Because of the involvement of ion channels in diverse biological functions, defects in the expression and functional activity of ion channels can cause disease in many tissues [8]. The number of human diseases related with ion channel malfunction has grown rapidly over the past few years $[4,9,10]$. In particular, there is increasing evidence that ion channels, including both voltage-gated and ligand-gated channels, are involved in the progression and pathology of diversified human cancers [6,7,11-17]. For example, voltage-gated potassium $\left(\mathrm{K}^{+}\right)(\mathrm{Kv})$ channels and calcium $\left(\mathrm{Ca}^{2+}\right)$-activated $\mathrm{K}^{+}$ $\left(\mathrm{K}_{\mathrm{Ca}}\right)$ channels are known to control tumor cell proliferation through the modulation of membrane potential in breast, colon, and prostate cancers [12,14,15]. Transient

\section{Biomed Central}

(c) 2013 Ko et al.; licensee BioMed Central Ltd. This is an Open Access article distributed under the terms of the Creative Commons Attribution License (http://creativecommons.org/licenses/by/2.0), which permits unrestricted use, distribution, and reproduction in any medium, provided the original work is properly cited. 
receptor potential (TRP) channels are involved in vascular permeability and angiogenesis and have been implicated in tumor growth and metastasis $[18,19]$. Several ligand-gated channels, such as nicotinic acetylcholine receptors, affect neoplastic progression by regulating tumor cell proliferation, apoptosis, and angiogenesis [20-23]. More importantly, the expression level of ion channels is potentially able to serve as a prognostic index in human cancers for clinical purposes. For instance, TRPM1, a TRP cation channel, is an indicator of melanoma aggressiveness [24] and expression of the $\mathrm{Ca}^{2+}$-selective cation channel TRPV6 is a prognostic marker for tumor progression in human prostate cancer [25]. In addition, the long TRP channel TRPM8 might serve as a prognostic marker for androgenunresponsive and metastatic prostate cancer [26] and the expression of $S C N 9 A$, a voltage-gated sodium $\left(\mathrm{Na}^{+}\right)$ channel, is also useful for prognostic purposes in prostate cancer [27].

Breast cancer is the most common invasive cancer in women worldwide. It is also the principal cause of death from cancer among women globally [28]. A large number of breast cancer studies sought to understand the molecular mechanisms of cancer origin, progression, and invasion that lead to metastasis, and many of these studies have underlined the involvement of ion channels in breast cancer. For example, $\mathrm{K}_{\mathrm{Ca}}$ channels contribute to breast tumor migration and progression $[29,30]$ and TRP channels are strongly correlated with breast tumor cell proliferation [31]. In addition, the upregulation of several voltage-gated $\mathrm{Na}^{+}(\mathrm{NaV})$ channels is associated with metastatic process in breast cancer [32]; however, most of these studies focus on only one ion channel or one type of ion channel. So far, there is no clear picture on the overall expression profiling of different ion channel genes in breast cancer. High-throughput "omic" technologies make it possible to scan all ion channel genes rather than focusing on a single gene or gene family [33]. In this study, we looked to identify molecular signatures consisting of multiple genes from different ion channel families that are implicated in the pathology of human breast cancer. Firstly, we investigated the association of ion channel genes with p53 mutation status in breast tumors. The tumor suppressor p53 is known to play a critical role in regulating the cell cycle and is thus involved in preventing cancer. Mutations in p53 are strongly associated with poor clinical outcome in breast cancer patients $[15,23]$. Comparison between the p53 mutant and wild-type groups showed that ion channel genes are associated with more aggressive and therapeutically refractory tumors [15]. Secondly, we identified the ion channel genes that were differentially expressed between estrogen receptor (ER) positive and negative breast cancer patients. About $75 \%$ of all breast cancers are ER positive, which grow in response to the hormone estrogen. ER is a powerful prognostic marker and an efficient target for the treatment of hormone-dependent breast cancer [26]. Identification of the ER-related ion channels helps us understand the role of ER in the development and progression of breast cancer. Thirdly, we investigated the relationship between ion channel gene expression and histological tumor grade in breast cancer. We identified a molecular signature consisting of 30 ion channel genes (IC30), which significantly correlated with tumor grade. We demonstrate that IC30 is a robust prognostic biomarker to predict clinical outcome in breast cancer, and is independent of standard clinical and pathological prognostic factors including patient age, lymph node status, tumor size, tumor grade, ER status, and progesterone receptor (PR) status. The performance of IC30 was also validated in several independent cohorts from different parts of the world (Table 1).

\section{Results}

\section{Differentially expressed ion channel genes between p53} mutant and wild-type tumors

280 ion channel genes were collected for this study (Additional file 1: Table S1). We aim to identify candidate ion channels that are implicated in breast cancer based on gene expression profiling. We first explored the difference in ion channel gene expression between p53 mutant and wild-type breast tumors in the discovery SIN cohort. There were 58 samples with p 53 mutations resulting in protein-level changes and 193 samples with a wild-type genotype [15]. In total, 22 ion channel genes were identified as differentially expressed between the two groups. Five ion channel genes were upregulated in p53 mutant tumors, including KCNE3, KCNN4, and MCOLN2; while 17 ion channel genes were downregulated, including ANO1, KCNMA1, and TPCN1 (Table 2 and Figure 1). Among these differentially expressed genes, all the $\mathrm{Ca}^{2+}$ channel (CACNA1D, CACNA2D1, and CACNA2D2) and $\mathrm{Na}^{+}$(SCN7A and $S C N N 1 A$ ) channel genes were downregulated in mutant tumors. In contrast, the expression pattern of $\mathrm{K}^{+}$channel and chloride $\left(\mathrm{Cl}^{-}\right)$channels was more heterogeneous. Genome-scale inspection indicated a significant enrichment of ion channel genes among the genes regulated by p53 mutation status ( $P=0.027$ by Fisher's exact test).

To test the reliability of the above results in another cohort, we accessed a publicly available microarray dataset on breast cancer (FRA) where p53 mutation status was known. Unsupervised hierarchical cluster analysis demonstrated a very similar expression pattern of the 22 differentially expressed ion channel genes between the SIN and FRA cohorts (Figure 2). We evaluated the statistical significance in hierarchical cluster analysis by approximately unbiased $P$-value $(A U)$ (see Methods for details). In the SIN cohort, the hierarchical 
Table 1 Gene expression datasets of breast cancer

\begin{tabular}{|c|c|c|c|}
\hline Organization of data source & Abbreviation & GEO accession & Reference \\
\hline Genome Institute of Singapore, Singapore & $\mathrm{SIN}$ & GSE3494 & [15] \\
\hline Institut Paoli-Calmettes Marseille, France & FRA & GSE21653 & [16] \\
\hline Siemens Medical Solutions Diagnostics GmbH, Germany & GER & GSE11121 & [34] \\
\hline Netherlands Cancer Institute, Netherlands & NED & $-{ }^{a}$ & [21] \\
\hline Karolinska Institutet, Sweden & SWE & GSE1456 & [18] \\
\hline Koo Foundation SYS Cancer Center, Taiwan & TWN & GSE20685 & [19] \\
\hline Nuvera Biosciences Inc, United States & USA1 & GSE25066 & [20] \\
\hline Veridex LLC, United States & USA2 & GSE2034 & {$[27]$} \\
\hline
\end{tabular}

${ }^{a}$ Expression data for NED are publicly available from http://bioinformatics.nki.nl/data.php.

clusters of upregulated and downregulated genes were highly robust $(A U=0.993$ for the upregulated cluster and $A U=0.963$ for the downregulated cluster). Similar results were obtained for the FRA cohort $(A U=0.985$ for the upregulated cluster and $A U=0.990$ for the downregulated cluster). Two-tailed t-tests also indicated that 15 out of the 22 genes were significantly (adjusted $P<0.05)$ dysregulated between p53 mutant and wildtype tumors in the FRA cohort (Additional file 1: Table
S2). The direction of differential expression in the SIN cohort was reproduced in the FRA cohort (Figure 3A).

\section{Differentially expressed ion channel genes between ER positive and negative patients}

We compared ion channel gene expression between ER positive and negative patients in the SIN cohort. A total of 213 patients were identified as ER positive while 34 patients were identified as ER negative. Twenty-four ion

Table 2 Comparison in gene expression level between p53 mutant and wild-type tumors

\begin{tabular}{|c|c|c|c|}
\hline $\begin{array}{l}\text { Gene } \\
\text { symbol }\end{array}$ & Gene title & $\begin{array}{r}\text { Fold } \\
\text { change }^{\mathrm{a}}\end{array}$ & $\begin{array}{r}\text { Adjusted } \\
P \text {-value }\end{array}$ \\
\hline ANO1 & anoctamin 1, calcium activated chloride channel & 0.66 & 0.001 \\
\hline CACNAID & calcium channel, voltage-dependent, $L$ type, alpha 1D subunit & 0.32 & $<0.001$ \\
\hline CACNA2D1 & calcium channel, voltage-dependent, alpha 2/delta subunit 1 & 0.79 & 0.002 \\
\hline CACNA2D2 & calcium channel, voltage-dependent, alpha 2/delta subunit 2 & 0.47 & $<0.001$ \\
\hline CLCA2 & chloride channel accessory 2 & 2.53 & 0.039 \\
\hline CLIC5 & chloride intracellular channel 5 & 0.77 & $<0.001$ \\
\hline CLIC6 & chloride intracellular channel 6 & 0.28 & $<0.001$ \\
\hline GLRB & glycine receptor, beta & 0.32 & $<0.001$ \\
\hline KCND3 & potassium voltage-gated channel, Shal-related subfamily, member 3 & 0.46 & $<0.001$ \\
\hline KCNE3 & potassium voltage-gated channel, Isk-related family, member 3 & 1.34 & $<0.001$ \\
\hline KCNE4 & potassium voltage-gated channel, Isk-related family, member 4 & 0.25 & $<0.001$ \\
\hline KCNJ3 & potassium inwardly-rectifying channel, subfamily J, member 3 & 0.51 & $<0.001$ \\
\hline KCNK1 & potassium channel, subfamily K, member 1 & 1.44 & $<0.001$ \\
\hline KCNK6 & potassium channel, subfamily K, member 6 & 0.80 & 0.010 \\
\hline KCNMA1 & potassium large conductance calcium-activated channel, subfamily M, alpha member 1 & 0.65 & $<0.001$ \\
\hline KCNN4 & potassium intermediate/small conductance calcium-activated channel, subfamily N, member 4 & 1.69 & $<0.001$ \\
\hline MCOLN2 & mucolipin 2 & 1.60 & $<0.001$ \\
\hline$P 2 R \times 4$ & purinergic receptor $\mathrm{P} 2 \mathrm{X}$, ligand-gated ion channel, 4 & 0.73 & $<0.001$ \\
\hline SCN7A & sodium channel, voltage-gated, type VII, alpha subunit & 0.29 & $<0.001$ \\
\hline SCNNIA & sodium channel, non-voltage-gated 1 alpha subunit & 0.71 & $<0.001$ \\
\hline TPCN1 & two pore segment channel 1 & 0.77 & $<0.001$ \\
\hline TRPC1 & transient receptor potential cation channel, subfamily C, member 1 & 0.72 & 0.005 \\
\hline
\end{tabular}

${ }^{a}$ Fold change is calculated by dividing the mean expression of p53 mutant tumor by the mean expression of p53 wild-type tumor.

${ }^{\mathrm{b}} P$-value is calculated by two-tailed $t$-test and adjusted by Benjamini \& Hochberg correction. 


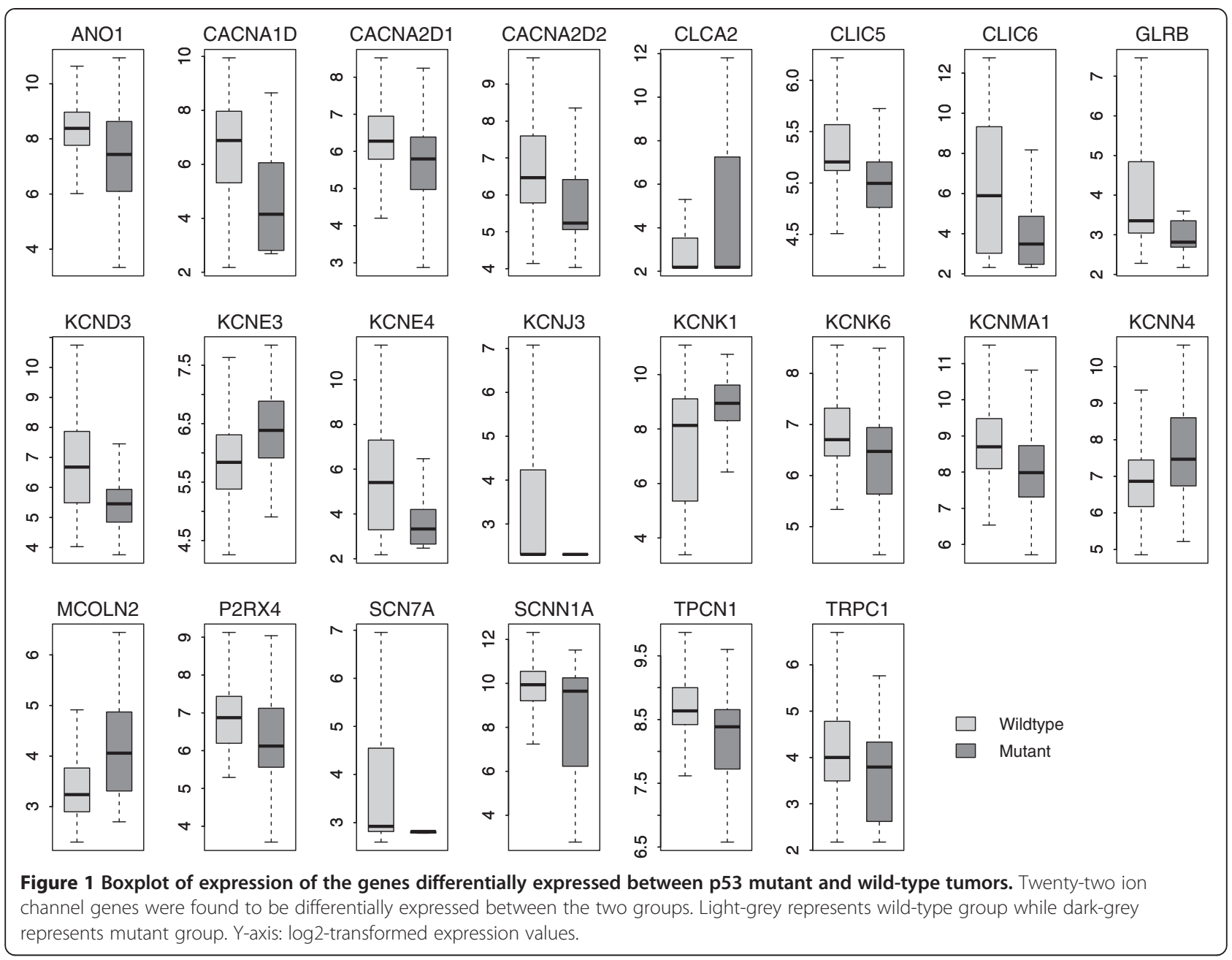

channel genes were identified as differentially expressed between the two groups; 16 genes were upregulated in ER positive patients while 8 genes were downregulated (Table 3 and Figure 4). Among these differentially expressed genes, all the $\mathrm{Ca}^{2+}$ channels (except CACNA1A) and $\mathrm{Na}^{+}$channel genes were upregulated in the ER positive group, whereas the expression pattern of $\mathrm{K}^{+}$channel and $\mathrm{Cl}^{-}$channels was more heterogeneous. Nineteen out of the 24 differentially expressed genes overlapped with the genes differentially expressed between p53 mutant and wild-type tumors (Figures 1 and $4)$, which is statistically significant $(P<0.001$ by cumulative hypergeometric distribution function). Among these common genes, all the downregulated genes in ER positive patients were upregulated in the p53 mutant group and vice versa, which is consistent with previous findings that patients with negative ER status share common pathology with patients harboring mutant p53 $[25,35]$. We also found a significant enrichment of ion channel genes among the genes dysregulated by ER status $(P=0.013$ by Fisher's exact test).
We next checked the expression profiling the 24 ER status related ion channel genes in three independent cohorts (FRA, USA1, and USA2) where ER status was known. The heatmaps generated by unsupervised hierarchical cluster analysis demonstrated an analogous expression profiling for the 24 ion channel genes among the discovery and validation cohorts (Additional file 2: Figures S1, S2, S3 and S4). A side-by-side comparison between Table 3 and Additional file 1: Table S3 revealed that the 24 genes were significantly (adjusted $P<0.05$ ) dysregulated by ER status in at least one out of the three validation cohorts. The direction of differential expression in the SIN cohort was consistent with that in the FRA, USA1, and USA2 cohorts (Figure 3B).

\section{Correlation between tumor grade and expression of ion channel genes}

To determine the relationship between tumor progression and ion channel gene expression, we linked gene expression level with histological tumor grade in the SIN cohort, using the Spearman's rank correlation test. The 


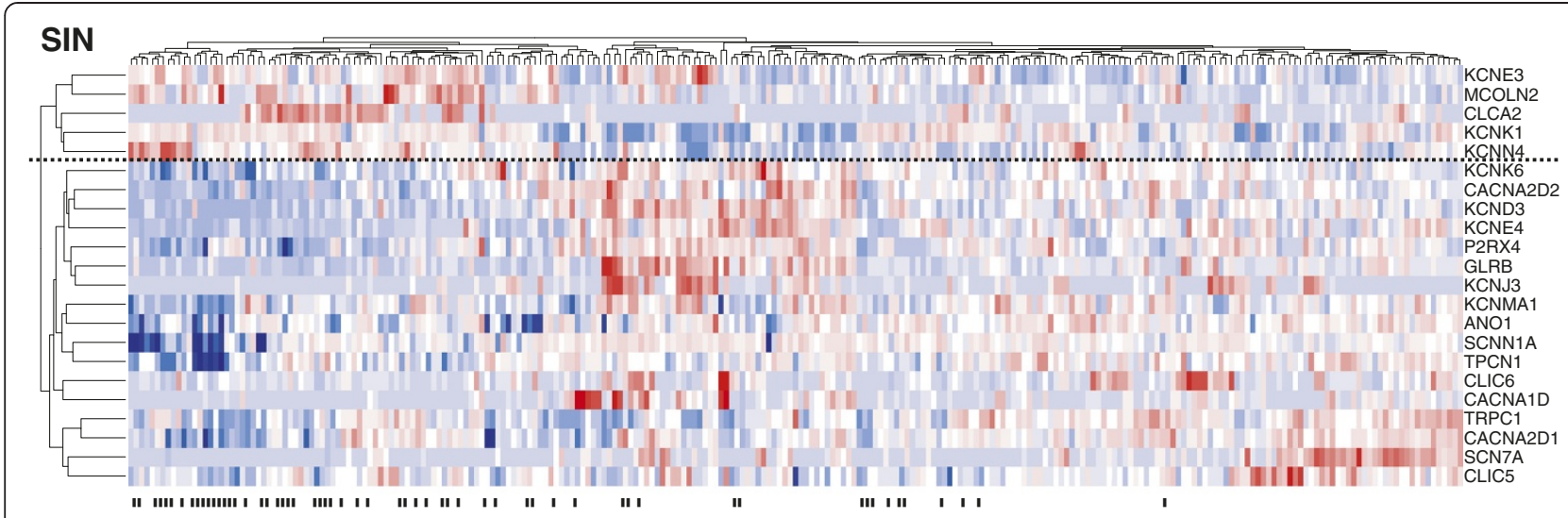

\section{FRA}

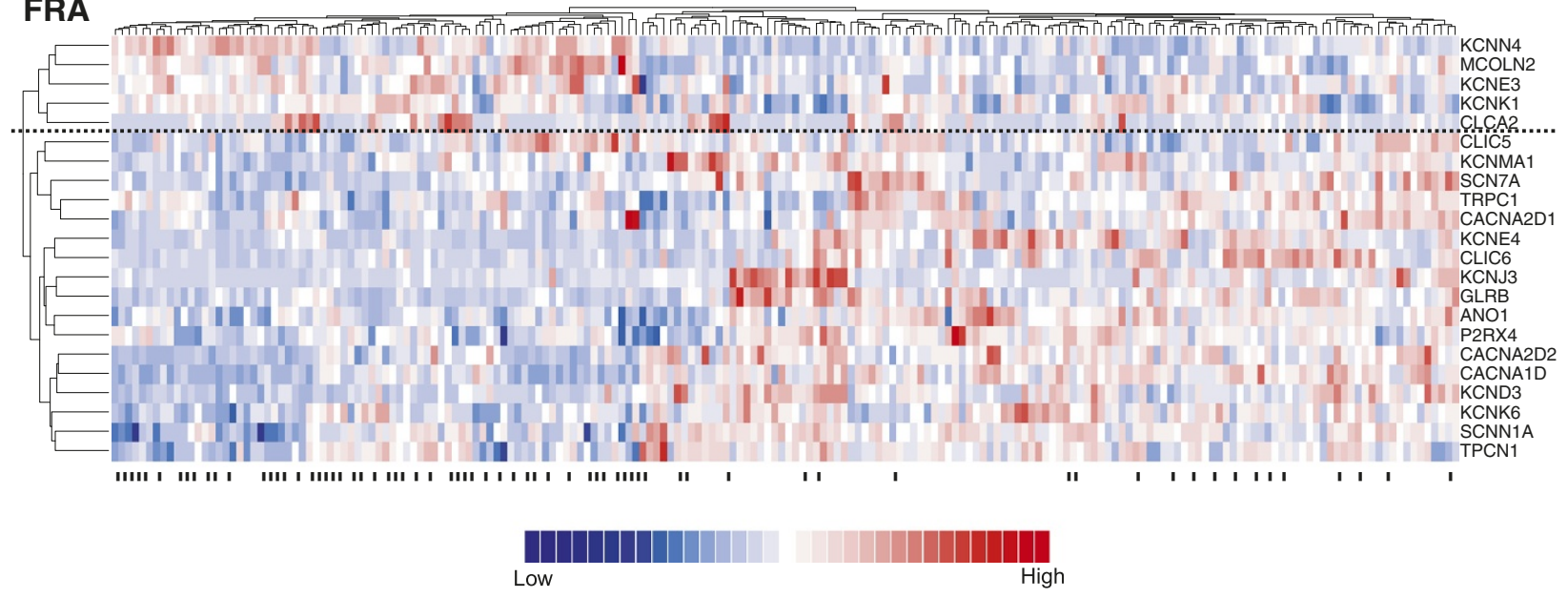

Figure 2 Heatmaps of expression of the genes differentially expressed between p53 mutant and wild-type tumors. The differentially expressed ion channel genes were derived from the discovery cohort (SIN) and verified in the FRA cohort. Each row in the heatmaps was labelled with the corresponding gene symbol. The columns labelled with "-" denote p53 mutant tumors. Red represents relatively increased gene expression while blue represents down-regulation. The horizontal dotted line separates the down- and up- regulated gene clusters.

expression of 30 ion channel genes was found to be significantly (adjusted $P<0.05$ ) correlated with tumor grade (Table 4). Eleven out of the 30 genes showed a positive correlation between expression and tumor grade while the other 19 genes showed a negative pattern (Figure 5). Given the fact that tumor grade reflects the differentiation of breast cancer cells, we identified 11 upregulated and 19 downregulated ion channel genes in more aggressive breast tumors. Among these 30 genes, 19 genes were also differentially expressed between the p53 mutant and wild-type tumors. The number of the overlapping dysregulated genes was statistically significant $(P<0.001$ by cumulative hypergeometric distribution function). Positive correlation between expression and tumor grade corresponds to upregulation in p53 mutant tumors and vice versa, which confirms the wellestablished findings that p53 mutations link to highergrade breast cancer and potentially poorer clinical outcomes [32,33,36,37]. Similar to the results described above for p53/ER status, ion channel genes were also significantly enriched among all the genes that were regulated by tumor grade ( $P=0.003$ by Fisher's exact test).

Because of the availability of tumor grade information in the FRA, GER, and USA1 cohorts, we tested the expression pattern of the above 30 genes in these 3 independent datasets. We observed a significant correlation between the expression and tumor grade in at least one validation cohort for each gene, except for TPCN2 (Additional file 1: Table S4). The correlation coefficients for each gene were largely concordant across the discovery and validation cohorts (Figure 3C).

\section{Prognostic molecular signature composed of ion channel genes}

We hypothesized that the 30 ion channel genes associated with tumor histological grade would be predictive of tumor outcome in breast cancer patients. We designated these ion channel genes as the IC30 gene 

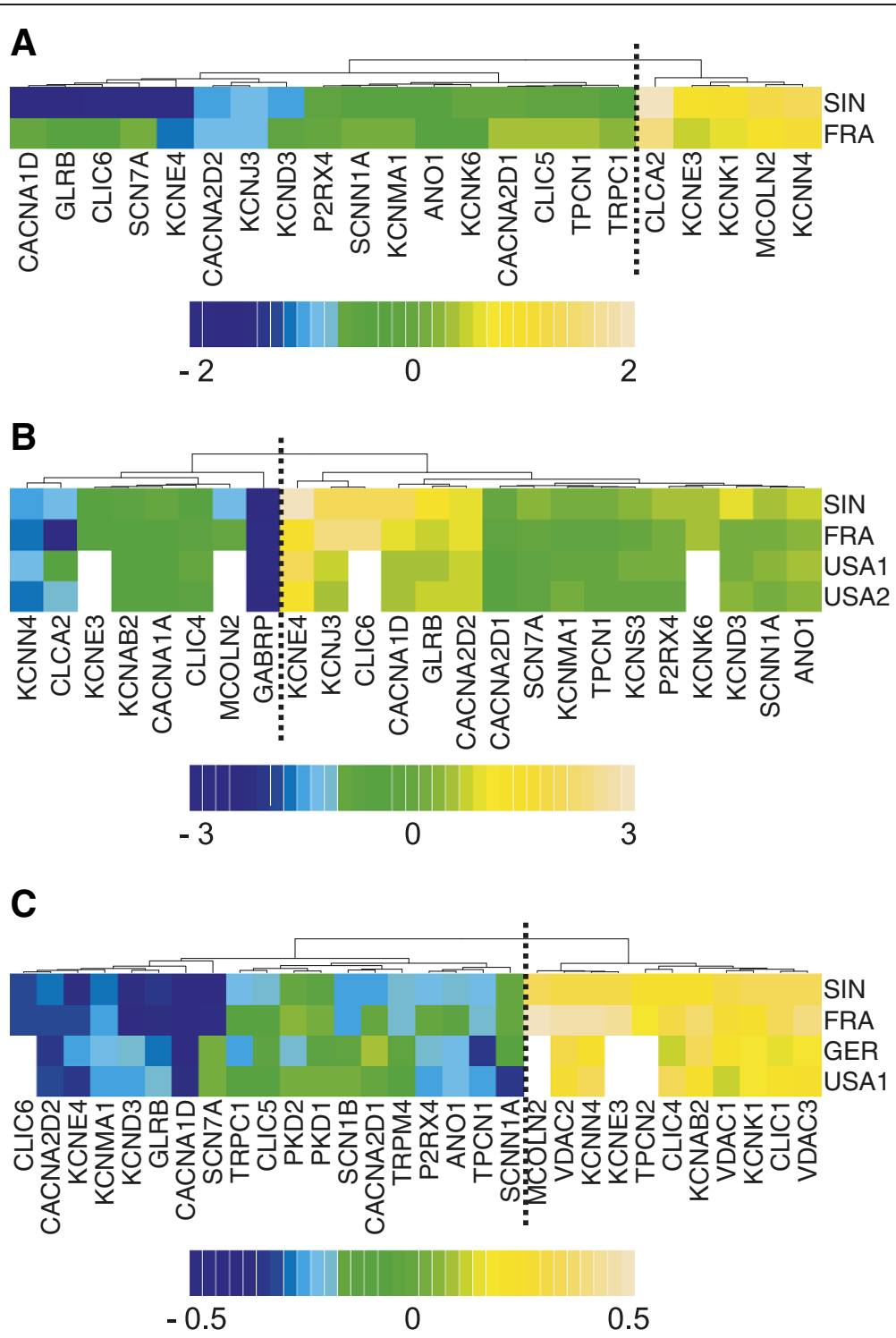

Figure 3 Validation of ion channel gene expression profiling in breast cancer. (A) Heatmap of log2-transformed fold change of gene expression level between p53 mutant and wild-type tumors (mutant/wild-type). In the SIN cohort, 5 genes were up-regulated (log2-transformed fold change $>0$ ) while 17 genes were down-regulated (log2-transformed fold change $<0$ ) in mutant tumors. The vertical dotted line separates the down- and up- regulated gene clusters ( $A U=1$ for both clusters). (B) Heatmap of log2-transformed fold change of gene expression level between ER positive and negative groups (ER positive/negative). In the SIN cohort, 16 genes were up-regulated (log2-transformed fold change > 0 ) while 8 genes were down-regulated (log2-transformed fold change $<0$ ) in ER positive patients. The white cells in the heatmap mean the gene expression data are unavailable in the corresponding datasets. The vertical dotted line separates the down- and up- regulated gene clusters ( $A U=$ 0.995 for both clusters). (C) Heatmap of Spearman's rank correlation coefficient. We found 30 ion channel genes with significant Spearman's rank correlation between gene expression and histological grade in SIN cohort. Correlation coefficient $>0$ means that gene is upregulated in the patients with higher grade while negative correlation coefficient indicates down-regulation in the patients with higher grade. The white cells in the heatmap mean the gene expression data are unavailable in the corresponding datasets. The vertical dotted line separates the down- and up- regulated gene clusters ( $A U=1$ for both clusters).

signature. We developed a risk scoring system that combined gene expression information in the IC30 with the Spearman's rank correlation coefficients $(\rho)$ listed in Table 4. IC30 positive patients were defined as those having a risk score greater than the group median score and the other patients were assigned as IC30 negative.
We tested the ability of the risk score to stratify patients into prognostic groups in the SIN cohort and the seven validation cohorts (FRA, GER, NED, SWE, TWN, USA1, and USA2). Kaplan-Meier survival analyses were used to compare the IC30 positive and negative groups and determined statistical significance by log-rank tests. The 
Table 3 Comparison in gene expression level between ER positive and negative tumors

\begin{tabular}{|c|c|c|c|}
\hline $\begin{array}{l}\text { Gene } \\
\text { symbol }\end{array}$ & Gene title & $\begin{array}{r}\text { Fold } \\
\text { change }^{a}\end{array}$ & $\begin{array}{l}\text { Adjusted } \\
P \text {-value }\end{array}$ \\
\hline ANO1 & anoctamin 1, calcium activated chloride channel & 2.09 & $<0.001$ \\
\hline CACNATA & calcium channel, voltage-dependent, P/Q type, alpha 1A subunit & 0.65 & 0.043 \\
\hline CACNAID & calcium channel, voltage-dependent, L type, alpha 1D subunit & 5.59 & $<0.001$ \\
\hline CACNA2D1 & calcium channel, voltage-dependent, alpha 2/delta subunit 1 & 1.30 & 0.033 \\
\hline CACNA2D2 & calcium channel, voltage-dependent, alpha 2/delta subunit 2 & 2.61 & $<0.001$ \\
\hline CLCA2 & chloride channel accessory 2 & 0.46 & 0.017 \\
\hline CLIC4 & chloride intracellular channel 4 & 0.75 & 0.008 \\
\hline CLIC6 & chloride intracellular channel 6 & 5.86 & $<0.001$ \\
\hline GABRP & gamma-aminobutyric acid (GABA) A receptor, pi & 0.20 & 0.020 \\
\hline GLRB & glycine receptor, beta & 3.42 & $<0.001$ \\
\hline KCNAB2 & potassium voltage-gated channel, shaker-related subfamily, beta member 2 & 0.72 & 0.013 \\
\hline KCND3 & potassium voltage-gated channel, Shal-related subfamily, member 3 & 2.36 & $<0.001$ \\
\hline KCNE3 & potassium voltage-gated channel, Isk-related family, member 3 & 0.75 & 0.003 \\
\hline KCNE4 & potassium voltage-gated channel, Isk-related family, member 4 & 12.64 & $<0.001$ \\
\hline KCNJ3 & potassium inwardly-rectifying channel, subfamily J, member 3 & 6.22 & $<0.001$ \\
\hline KCNK6 & potassium channel, subfamily K, member 6 & 1.82 & $<0.001$ \\
\hline KCNMA1 & potassium large conductance calcium-activated channel, subfamily M, alpha member 1 & 1.45 & 0.035 \\
\hline KCNN4 & potassium intermediate/small conductance calcium-activated channel, subfamily N, member 4 & 0.42 & $<0.001$ \\
\hline KCNS3 & potassium voltage-gated channel, delayed-rectifier, subfamily S, member 3 & 1.58 & 0.028 \\
\hline MCOLN2 & mucolipin 2 & 0.46 & 0.002 \\
\hline P2RX4 & purinergic receptor P2X, ligand-gated ion channel, 4 & 1.82 & $<0.001$ \\
\hline SCN7A & sodium channel, voltage-gated, type VII, alpha subunit & 1.71 & 0.009 \\
\hline SCNN1A & sodium channel, non-voltage-gated 1 alpha subunit & 2.00 & $<0.001$ \\
\hline TPCN1 & two pore segment channel 1 & 1.38 & $<0.001$ \\
\hline
\end{tabular}

${ }^{a}$ Fold change is calculated by dividing the mean expression of ER positive tumor by the mean expression of ER negative tumor.

${ }^{\mathrm{b}} P$-value is calculated by two-tailed $t$-test and adjusted by Benjamini $\&$ Hochberg correction.

IC30 signature was able to identify patients with poor breast cancer survival in all the cohorts $(P<0.01)$ except for the GER cohort (a marginal $P=0.066$ ) (Figure 6). This association between IC30 status and survival was also confirmed by univariate Cox proportional hazard regression of survival. IC30 positive patients had a 1.98fold increased risk for death in the SIN cohort, 1.99-fold in the FRA cohort, 1.73-fold in the GER cohort, 1.81fold in the NED cohort, 4.33-fold in the SWE cohort, 1.82-fold in the TWN cohort, 3.11-fold in the USA1 cohort, and 1.71-fold in USA2 cohort (Table 5).

\section{Independence of IC30 from other clinicopathological factors}

We investigated the performance of the IC30 signature in comparison with clinicopathological variables associated with prognosis in breast cancer in the USA1 cohort, the largest dataset in this study. A multivariate Cox regression of survival indicated that IC30 status remained a significant covariate in relation to the standard clinicopathological factors in breast cancer, including patient age, lymph node status, tumor size, tumor grade, and ER and PR status (Table 6). Patients were stratified according to respective clinicopathological factors. For patients aged $<50$ and $\geq 50$, the IC30 positive patients had a significant 2.37 -fold $(P=0.003)$ and 4.21 -fold $(P<$ 0.001 ) increased risk for death, respectively. For patients with and without lymph node involvement, the IC30 positive patients had a 2.05 -fold $(P=0.157)$ and 2.72 -fold $(P<0.001)$ increased risk for death, respectively. For patients with tumor size $<\mathrm{T} 3$ and $\geq \mathrm{T} 3$, the IC30 positive patients had a significantly increased risk for death of 3.61 -fold $(P<0.001)$ and 2.78 -fold $(P<0.001)$, respectively. For patients with lower (1 or 2) and higher (3) tumor grade, the IC30 positive patients had a significantly 6.91 -fold $(P<0.001)$ and 1.67 -fold $(P=0.044)$ increased risk for death, respectively. For patients with ER negative and positive status, the IC30 positive patients had an increased risk for death of 1.30 -fold $(P=0.275)$ and 2.94-fold $(P=0.002)$, respectively. Lastly, IC30 


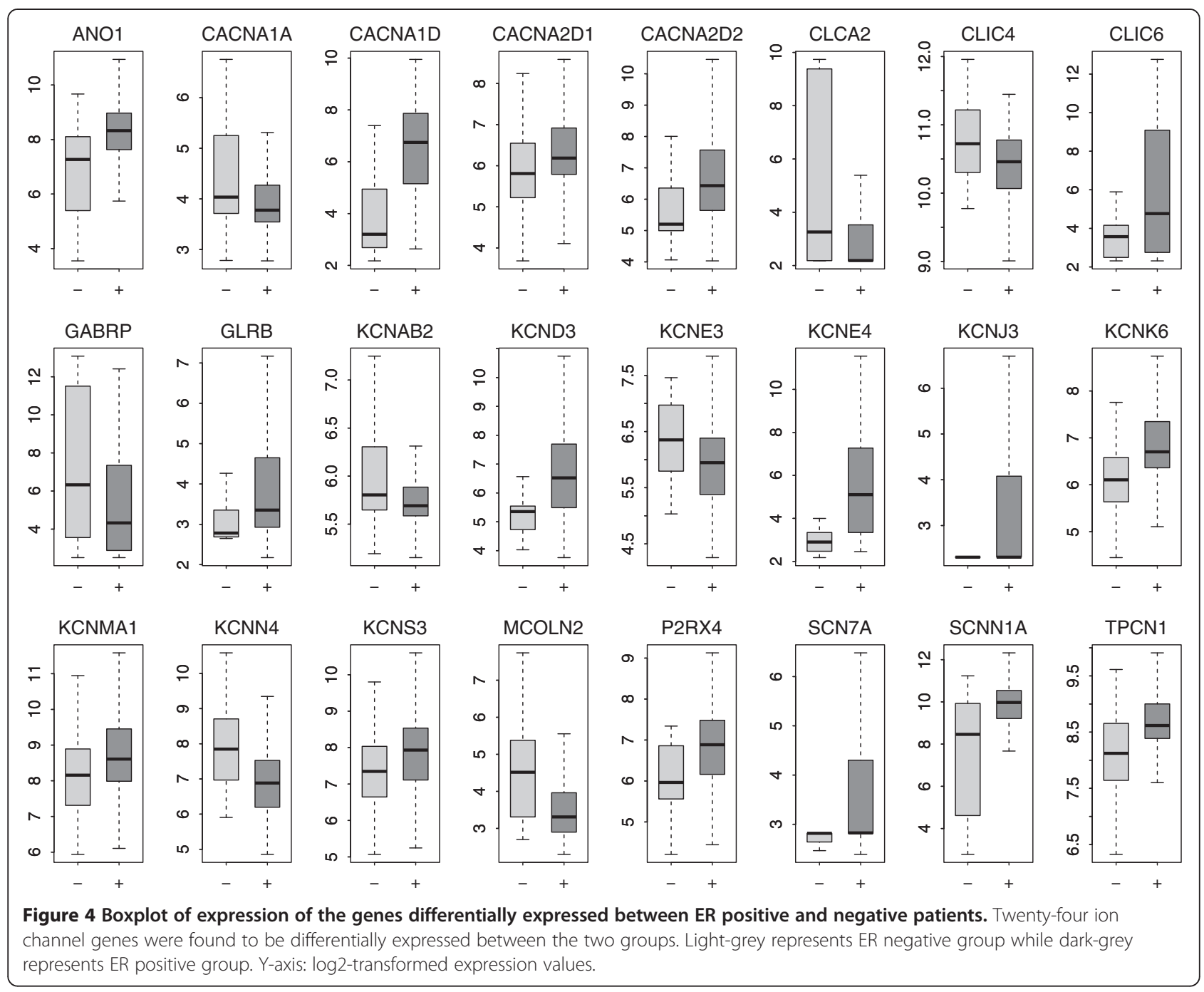

positive patients with $\mathrm{PR}$ negative and positive status had a significantly 1.65 -fold $(P=0.030)$ and 2.35 -fold $(P=0.021)$ increased risk for death, respectively. KaplanMeier survival analysis also demonstrated a significantly reduced survival for IC30 positive patients in each subset grouped by age, lymph node status, and tumor size (Figure 7). In addition, univariate Cox regressions of survival confirmed that the IC30 signature was a superior survival predictor in the USA1 cohort, in comparison with age, tumor size, and tumor grade (Additional file 1: Table S5).

We also checked the independent predictive power of the IC30 signature in the FRA cohort, where information on age, tumor grade, ER status, PR status, and p53 mutation status is available. A multivariate Cox regression of survival indicated that the IC30 signature was the only significant survival predictor $(P=0.014)$ (Table 7). Univariate Cox regressions of survival also confirmed that the IC30 signature was the most significant prognostic factor in the FRA cohort, in comparison with age, tumor grade, ER and PR status, and p53 mutation status (Additional file 1: Table S6). Taken together, these results suggest that IC30 is associated with clinical outcome and is an independent prognostic factor.

\section{Discussion}

Ion channels are implicated in many physiological processes and also play a pivotal role in the development of cancers; however, it is currently difficult to assign a specific mechanism for each ion channel in the proliferation, invasion, and metastasis of tumor cells [17,24]. Here, we investigated the pathological role of ion channel genes in breast cancer with respect to gene expression level. We tested the association of ion channel genes with p53 mutation status, ER status, and tumor histological grade: 22 ion channel genes were found to be dysregulated between p53 mutant and wild-type tumors, 24 ion channel genes were differentially expressed between ER positive and negative patients, and the expression level of 30 ion channel genes was significantly 
Table 4 Correlation between gene expression and histological tumor grade

\begin{tabular}{|c|c|c|c|}
\hline $\begin{array}{l}\text { Gene } \\
\text { symbol }\end{array}$ & Gene title & $\rho^{a}$ & $\begin{array}{l}\text { Adjusted } \\
P \text {-value }\end{array}$ \\
\hline ANO1 & anoctamin 1, calcium activated chloride channel & -0.23 & $<0.001$ \\
\hline CACNAID & calcium channel, voltage-dependent, $L$ type, alpha 1D subunit & -0.42 & $<0.001$ \\
\hline CACNA2D1 & calcium channel, voltage-dependent, alpha 2/delta subunit 1 & -0.28 & $<0.001$ \\
\hline CACNA2D2 & calcium channel, voltage-dependent, alpha 2/delta subunit 2 & -0.30 & $<0.001$ \\
\hline CLIC1 & chloride intracellular channel 1 & 0.26 & $<0.001$ \\
\hline CLIC4 & chloride intracellular channel 4 & 0.16 & 0.022 \\
\hline CLIC5 & chloride intracellular channel 5 & -0.22 & 0.001 \\
\hline CLIC6 & chloride intracellular channel 6 & -0.33 & $<0.001$ \\
\hline GLRB & glycine receptor, beta & -0.35 & $<0.001$ \\
\hline KCNAB2 & potassium voltage-gated channel, shaker-related subfamily, beta member 2 & 0.15 & 0.023 \\
\hline KCND3 & potassium voltage-gated channel, Shal-related subfamily, member 3 & -0.39 & $<0.001$ \\
\hline KCNE3 & potassium voltage-gated channel, Isk-related family, member 3 & 0.23 & $<0.001$ \\
\hline KCNE4 & potassium voltage-gated channel, Isk-related family, member 4 & -0.38 & $<0.001$ \\
\hline KCNK1 & potassium channel, subfamily K, member 1 & 0.25 & $<0.001$ \\
\hline KCNMA1 & potassium large conductance calcium-activated channel, subfamily M, alpha member 1 & -0.30 & $<0.001$ \\
\hline KCNN4 & potassium intermediate/small conductance calcium-activated channel, subfamily N, member 4 & 0.23 & $<0.001$ \\
\hline MCOLN2 & mucolipin 2 & 0.25 & $<0.001$ \\
\hline P2RX4 & purinergic receptor $\mathrm{P} 2 \mathrm{X}$, ligand-gated ion channel, 4 & -0.24 & $<0.001$ \\
\hline PKD1 & polycystic kidney disease 1 (autosomal dominant) & -0.17 & 0.012 \\
\hline PKD2 & polycystic kidney disease 2 (autosomal dominant) & -0.19 & 0.004 \\
\hline SCN1B & sodium channel, voltage-gated, type I, beta subunit & -0.27 & $<0.001$ \\
\hline SCN7A & sodium channel, voltage-gated, type VII, alpha subunit & -0.41 & $<0.001$ \\
\hline SCNN1A & sodium channel, non-voltage-gated 1 alpha subunit & -0.18 & 0.008 \\
\hline TPCN1 & two pore segment channel 1 & -0.26 & $<0.001$ \\
\hline TPCN2 & two pore segment channel 2 & 0.17 & 0.013 \\
\hline $\operatorname{TRPC1}$ & transient receptor potential cation channel, subfamily C, member 1 & -0.25 & $<0.001$ \\
\hline TRPM4 & transient receptor potential cation channel, subfamily M, member 4 & -0.21 & 0.002 \\
\hline VDAC1 & voltage-dependent anion channel 1 & 0.21 & 0.002 \\
\hline VDAC2 & voltage-dependent anion channel 2 & 0.22 & 0.001 \\
\hline VDAC3 & voltage-dependent anion channel 3 & 0.26 & $<0.001$ \\
\hline
\end{tabular}

${ }^{a} \rho$ is the Spearman's rank correlation coefficient.

${ }^{\mathrm{b}} P$-value is calculated by Spearman's rank correlation test and adjusted by Benjamini \& Hochberg correction.

correlated with histological grade. There is a large overlap between the three differentially expressed gene lists, which suggests a common ion channel-related biological mechanism underlying the different pathological phenotypes. The prognostic value of p53 mutation status has been well characterized in previous studies $[15,29-31,35]$. The frequency of p53 mutations is higher in ER negative breast cancer [25,35]. Mutant p53 and/or negative ER status are often associated with a high rate of proliferation, a high histological grade, and a poor prognosis [32,33,36,37]. Therefore, it is reasonable that several common ion channel genes are associated with p53 mutation status, ER status, and tumor histological grade, although the causal relationship between these three factors is still controversial.

Gene expression-based molecular signatures have been proven as prognostically valuable in several human cancers [38-42]. Gene signatures that work cooperatively with known clinicopathological factors may enhance prediction accuracy when identifying patients at higher risk for relapse and death. Our proposed molecular signature that is composed of 30 ion channel genes (IC30) associated with tumor grade is a promising prognostic marker. IC30 was solely developed based on the discovery cohort and its prognostic power of IC30 was validated in seven independent validation cohorts. We 


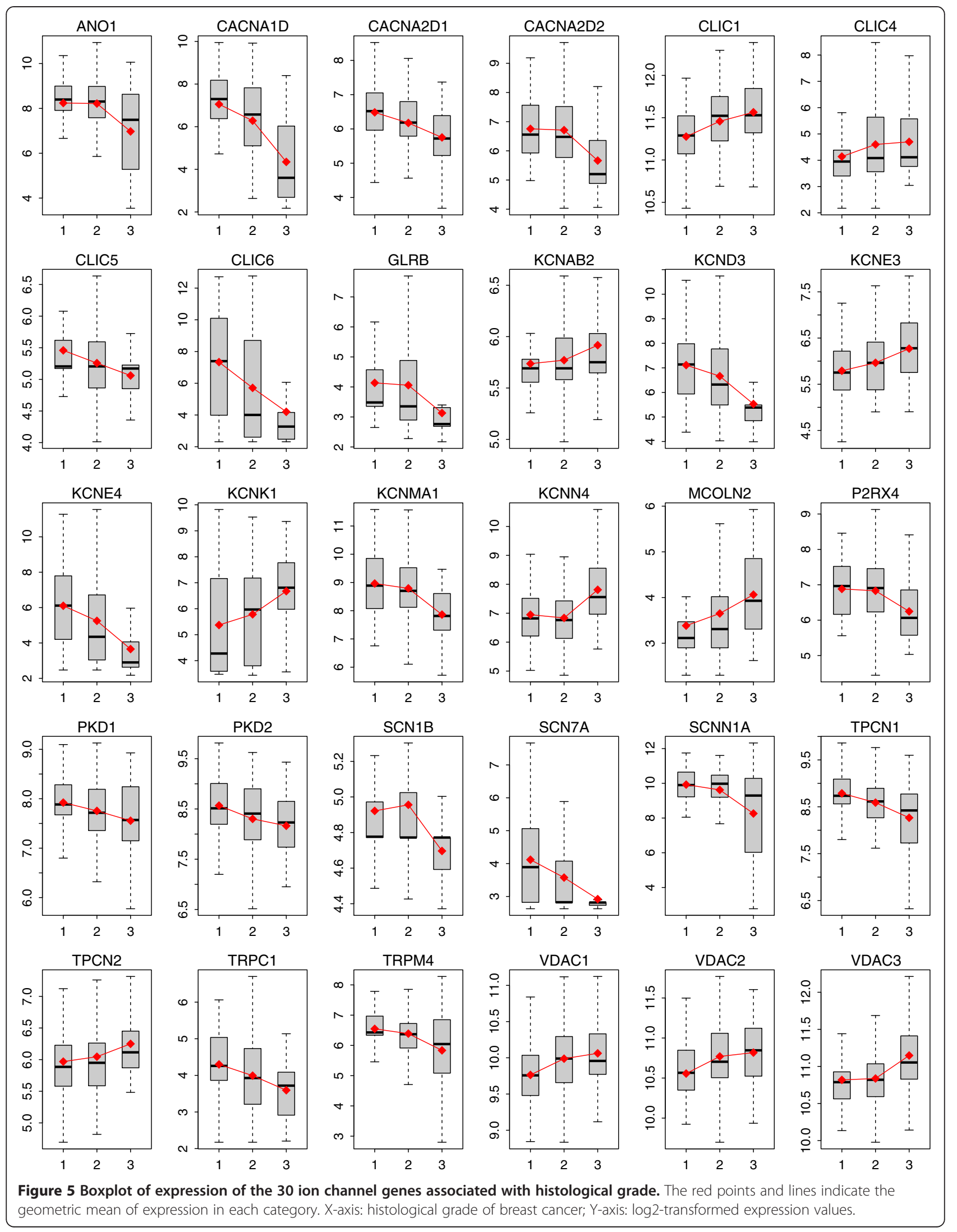




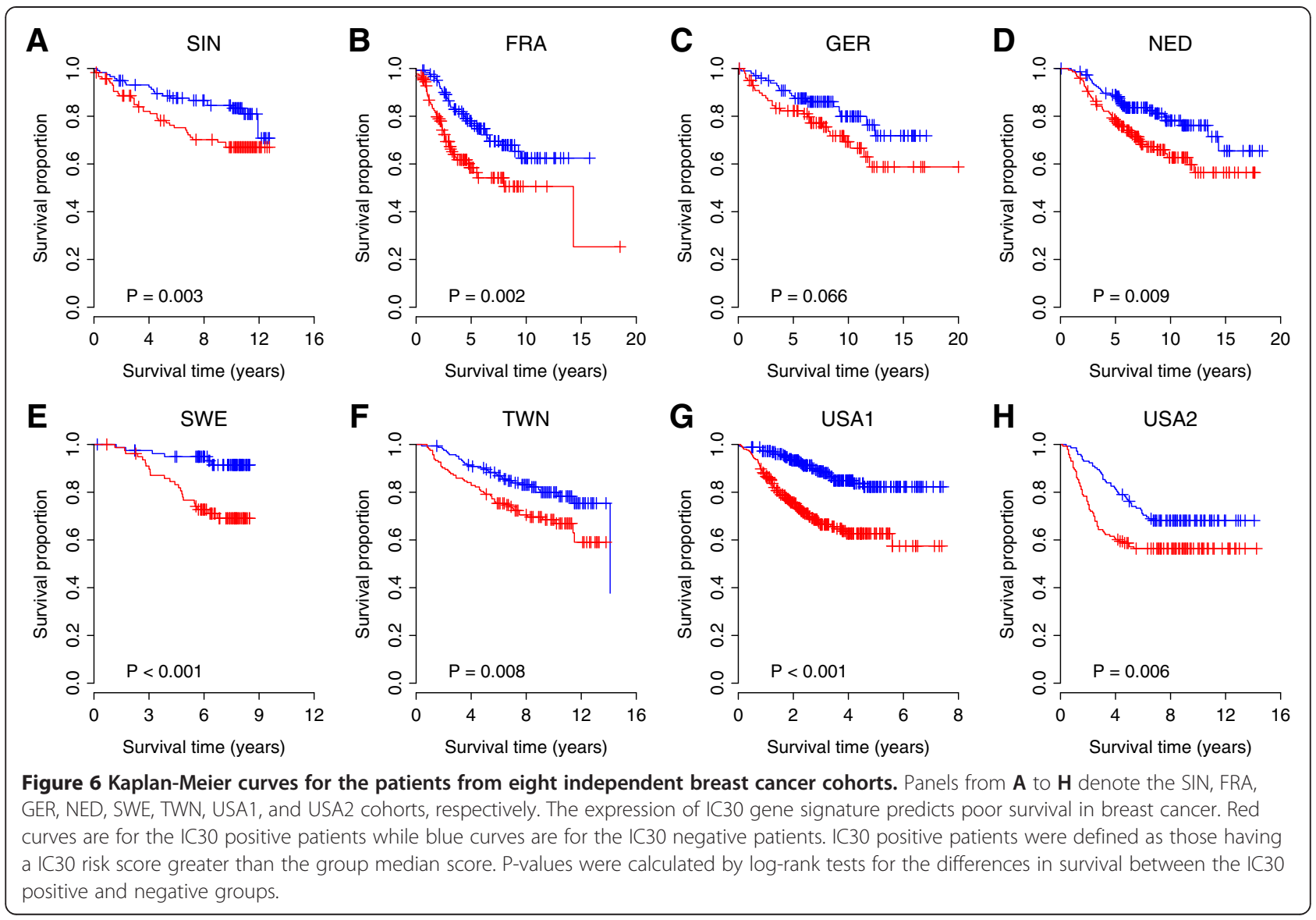

demonstrated that there were no significant multivariate interactions between IC30 status and other clinicopathological covariates. When grouped by age, tumor size, tumor grade, or PR status, the expression of IC30 further stratified breast cancer patients with significant differences in survival. A significantly increased risk of death was also observed in IC30 positive patients with positive lymph node status or positive ER status. However, a significant difference between IC30 positive and negative groups among the patients with negative ER status was not detected, which may be due to the

Table 5 Univariate Cox proportional hazards regression of survival by IC30 status for patients from 8 cohorts

\begin{tabular}{cccr}
\hline Cohort & Hazard ratio & 95\% Confidence interval & $\boldsymbol{P}$-value \\
\hline SIN & 1.98 & $(1.15,3.44)$ & 0.015 \\
FRA & 1.99 & $(1.28,3.10)$ & 0.002 \\
GER & 1.73 & $(0.96,3.14)$ & 0.069 \\
NED & 1.81 & $(1.15,2.86)$ & 0.010 \\
SWE & 4.33 & $(1.76,10.64)$ & 0.001 \\
TWN & 1.82 & $(1.17,2.85)$ & 0.008 \\
USA1 & 3.11 & $(2.05,4.70)$ & $<0.001$ \\
USA2 & 1.71 & $(1.16,2.51)$ & 0.006 \\
\hline
\end{tabular}

relatively smaller sample size in this category within the USA1 cohort. In addition, we only detected a marginal significant association for patients with negative lymph node status in the USA1 cohort, and a similar result was reproduced in the GER cohort. In fact, all patients from the GER cohort had negative lymph node status [34] and a marginally significant difference in the risk of death was observed between IC30 positive and negative patients in this cohort. Taken together with previous data, these results confirm that IC30 is not dependent on specific values of the respective covariates status, which enhances the identification of cancer patients at greater risk for death.

Although IC30 gene signature was identified using the tumor grade information, both multivariate and univariate Cox regressions of survival reveal that IC30 is superior to tumor grade, which suggests that the prognostic information contained in IC30 is not limited to tumor grade. Tumor grade only explains a small proportion of variation (less than 25\%) in expression of each IC30 gene. The significant association between tumor grade and IC30 gene expression specifically implies that IC30 genes are actively involved in tumor pathology in breast cancer. The combination of 30 genes contains more quantity of information than tumor grade itself. 
Table 6 Multivariate Cox proportional hazard regression of survival for the patients from the USA1 cohort

\begin{tabular}{lccr}
\hline Covariate & Hazard ratio & 95\% Confidence interval & $\boldsymbol{P}$-value \\
\hline IC30 + vs. - & 2.21 & $(1.32,3.70)$ & 0.002 \\
Age (per year) & 1.00 & $(0.98,1.02)$ & 0.940 \\
Lymph node + vs. - & 2.07 & $(1.35,3.16)$ & $<0.001$ \\
Tumor size $\geq$ T3 vs. $<$ T3 & 1.73 & $(1.16,2.57)$ & 0.007 \\
Grade 3 vs. 1,2 & 0.67 & $(0.41,1.11)$ & 0.119 \\
ER + vs. - & 0.58 & $(0.33,1.01)$ & 0.055 \\
PR + vs. - & 0.76 & $(0.45,1.31)$ & 0.330 \\
\hline
\end{tabular}

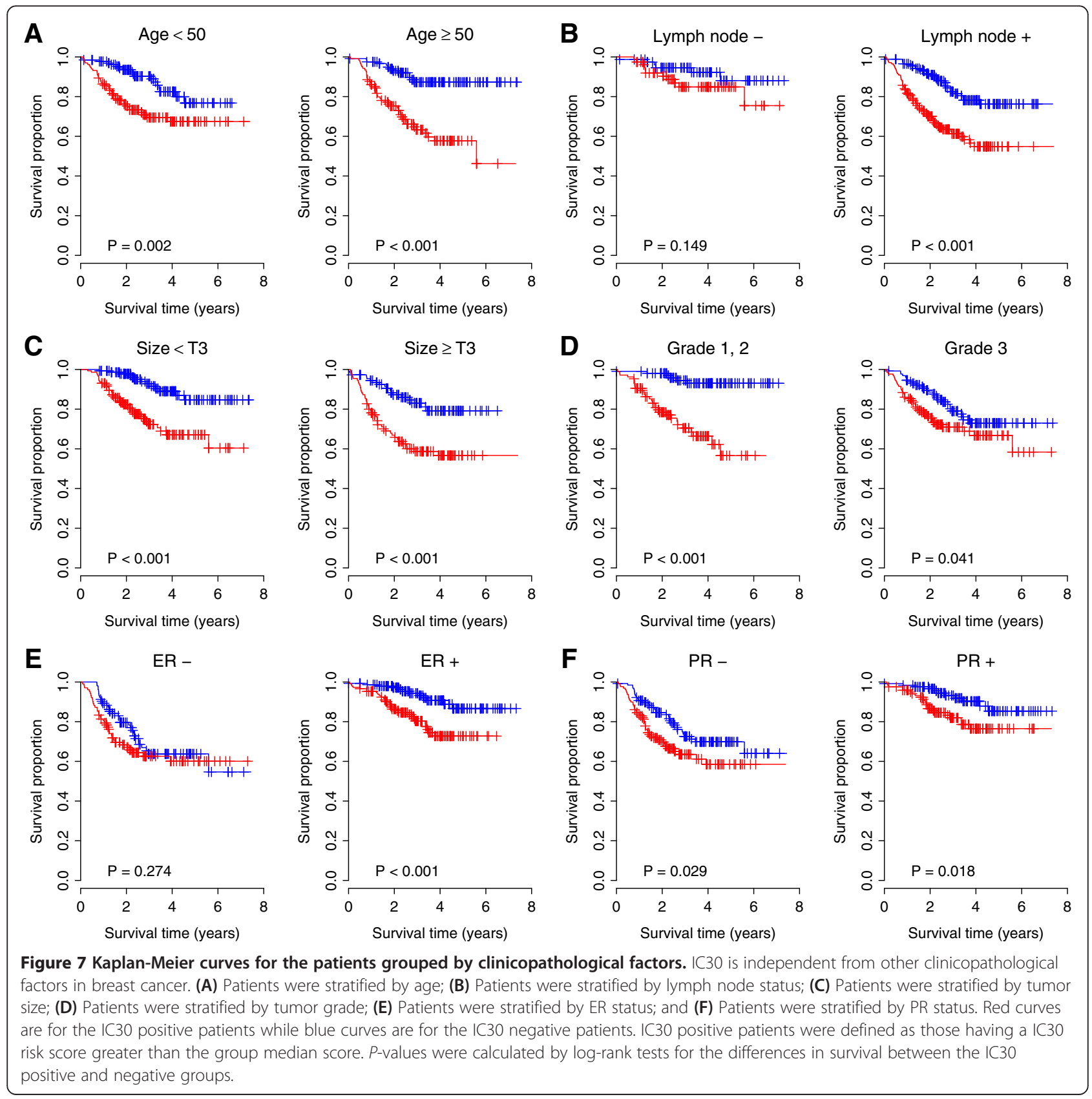


Table 7 Multivariate Cox proportional hazard regression of survival for the patients from the FRA cohort

\begin{tabular}{lccr}
\hline Covariate & Hazard ratio & 95\% Confidence interval & $P$-value \\
\hline IC30 + vs. - & 2.55 & $(1.21,5.39)$ & 0.014 \\
Age (per year) & 1.00 & $(0.98,1.02)$ & 0.687 \\
Grade 3 vs. 1,2 & 0.79 & $(0.43,1.45)$ & 0.444 \\
ER + vs. - & 0.91 & $(0.33,2.52)$ & 0.855 \\
PR + vs. - & 1.24 & $(0.48,3.18)$ & 0.655 \\
p53 mutant vs. wild-type & 1.22 & $(0.70,2.12)$ & 0.487 \\
\hline
\end{tabular}

Therefore, IC30 is based on tumor grade but not limited to tumor grade.

The involvement of ion channels in human cancer has been intensively studied in the past years. However, there is no broad consensus on the role and interplay between ion channels and cancer. Generally, ion channels are thought to "assist" cancer by tumor-related cellular behaviors such as proliferation, apoptosis, migration, or angiogenesis $[14,17,43,44]$. However, it is difficult to assign a detailed role for each ion channel in cancer pathology. In breast cancer, accumulating evidence indicates that $\mathrm{K}^{+}$channels play important roles in regulating tumor cell proliferation, cell cycle progression, and apoptosis $[12,45,46]$. Although a significant overexpression of $\mathrm{K}^{+}$channels has been correlated with human breast cancer cells [45,47-51], here we report a heterogeneous expression profiling in $\mathrm{K}^{+}$channel genes. Dysregulation in both directions was observed in $\mathrm{K}^{+}$ channel genes within the IC30. Four $\mathrm{K}^{+}$channel genes in the IC30 were upregulated in high-grade tumors. For example, KCNN4, encoding an intermediate conductance $\mathrm{K}_{\mathrm{Ca}}$ channel $\left(\mathrm{K}_{\mathrm{Ca}} 3.1\right)$, is among the upregulated $\mathrm{K}^{+}$ channel genes in the IC30 in high-grade tumors. The expression pattern of $\mathrm{K}_{\mathrm{Ca}} 3.1$ was confirmed by a recently published study where $\mathrm{K}_{\mathrm{Ca}} 3.1$ mRNA and protein were more highly expressed in grade 3 tumors than in both grades 1 and 2 [52]. On the contrary, three $\mathrm{K}^{+}$channel genes within the IC30 were downregulated in tumors with higher grade, which includes KCNMA1 encoding the BK channel alpha subunit. The negative correlation for $K C N M A 1$ between expression and tumor grade was in accord with four independent cohorts. However, increased expression of KCNMA1 was found in metastatic breast cancer in the brain compared to metastatic breast cancers in other organs [53], which suggests a more complicated pathological role for the BK channel in tumor metastasis.

Gene expression of $\mathrm{Cl}^{-}$channels also demonstrated a heterogeneous pattern in breast cancer. We reported two up- and two downregulated $\mathrm{Cl}^{-}$intracellular channel genes in high-grade tumors in the IC30. Among them, CLIC4 was found to be involved in skin cancer [54]; however, the exact role of CLIC4 is unclear. Besides $\mathrm{Cl}^{-}$ intracellular channels, the $\mathrm{Ca}^{+}$activated $\mathrm{Cl}^{-}$channel
CLCA2 was downregulated in breast cancer and is a candidate tumor suppressor gene [55]. We show here that the CLCA2 gene was upregulated in p53 mutant and/or ER negative breast tumors. In fact, the tumorigenicity of breast cancer was related with a loss of CLCA2 [56,57]. CLCA2 is a p53-inducible inhibitor of breast tumor proliferation [55]. However, the reason why CLCA2 expression is associated with p53 mutation status is beyond the scope of this study.

$\mathrm{Ca}^{2+}$ is an essential regulator of the cell cycle and is indispensable for cell proliferation [14]. Increased expression of voltage-gated $\mathrm{Ca}^{2+}$ channels has been observed in colon cancer cells [58] and small cell lung cancers [59]. However, all 3 voltage-gated $\mathrm{Ca}^{2+}$ ion channel genes in the IC30 were downregulated in p53 mutant tumors and/or high-grade tumors. Apart from these voltage-gated $\mathrm{Ca}^{2+}$ channels, the TRP family is also important to provide a $\mathrm{Ca}^{2+}$ influx pathway such that $\mathrm{Ca}^{2+}$ influx may occur through voltage-gated $\mathrm{Ca}^{2+}$ channels [14]. Several studies have demonstrated that the expression of TRP channels is significantly upregulated in breast tumor tissue and breast cancer cell lines [60-63], which is related to malignant growth and cancer progression [64]. However, a paradoxical result was observed in our study. PKD1, PKD2, and TRPC1, which are within the IC30 and belong to the TRP family, were downregulated in patients with p53 mutant tumors and/or of higher histological grade. This expression pattern is consistent in several of the validation cohorts.

Conflicting results were also seen in $\mathrm{Na}^{+}$channel genes. Decreased expression in high-grade tumors was found for the three $\mathrm{Na}^{+}$channel genes in the IC30, which was confirmed by the validation cohorts. However, increased expression of voltage-gated $\mathrm{Na}^{+}$channels has been reported in several cancer types, including breast, prostate, and lung cancer [65-68]. $\mathrm{Na}^{+}$channels were thought to enhance the invasiveness of cancer cells by increasing $\mathrm{H}^{+}$efflux [66] and by stimulating cysteine cathepsin activity [69]. The precise mechanism of $\mathrm{Na}^{+}$channels in tumor development remains unclear [70]. The discrepancy between our results and previous observation may be due to the discrepancy between mRNA expression, protein expression, and channel activity. Our study focused on mRNA abundance. However, protein expression and activity is not directly correlated to mRNA expression. Post-transcriptional 
regulatory mechanisms predominantly control cellular mRNA to protein abundance ratios [71].

Voltage-dependent anion channels (VDACs) are a class of ion channel located in the outer mitochondrial membrane [72]. We observed a consistent and significant positive correlation between gene expression and tumor grade for the three VDAC genes in the IC30. A recently published study indicated that higher $V D A C 1$ expression level predicts poor outcome in non-small cell lung cancers [73]. Here, we expanded this finding to breast cancer and the other 2 genes in VDAC family.

\section{Conclusions}

In summary, we investigated the gene expression profile of ion channels in breast cancer with respect to p53 mutation status, ER status, and histological grade. We show that there are numerous common ion channel genes, including ANO1, CACNA1D, CACNA2D1, CACNA2D2, CLIC6, GLRB, KCND3, KCNE4, KCNMA1, KCNN4, MCOLN2, P2RX4, SCN7A, SCNN1A, and TPCN1, that are differentially expressed with a change in p53 mutation status, ER status, and histological grade. The expression pattern of some ion channels, including several potassium, calcium, and sodium channels, is contradictory to previously published results derived from breast cancer cell lines, animal models, and/or human patients. We also identified a molecular gene signature IC30, which represents a promising diagnostic and prognostic biomarker in breast cancer. Further investigation into the role of ion channels in tumor pathology could provide new targets for therapy in multiple human cancers.

\section{Methods}

\section{Ion channel genes}

The definition of human ion channel genes was obtained from IUPHAR-DB [74] and GeneCards [5,9]. In total, we collected 280 ion channel genes, including $5 \mathrm{Ca}^{+}$activated $\mathrm{Cl}^{-}$channels, $6 \mathrm{Cl}^{-}$intracellular channels, 9 voltagesensitive $\mathrm{Cl}^{-}$channels, 1 mid-1-related $\mathrm{Cl}^{-}$channel, $12 \mathrm{~K}_{\mathrm{ca}}$ channels, $48 \mathrm{Kv}$ channels, 26 voltage-gated $\mathrm{Ca}^{+}$channels, $14 \mathrm{NaV}$ channels, 15 two-pore $\mathrm{K}^{+}$channels, 9 CatSper and two-pore channels, 16 inwardly rectifying $\mathrm{K}^{+}$channels, 4 non-voltage-gated $\mathrm{Na}^{+}$channels, 28 TRP channels, 10 cyclic nucleotide-regulated channels, $20 \mathrm{GABA}_{\mathrm{A}}$ receptors, 5 $5-\mathrm{HT}_{3}$ receptors, 5 glycine receptors, 18 ionotropic glutamate receptors, 16 nicotinic acetylcholine receptors, 7 P2X receptors, 3 voltage-dependent anion channels, 1 voltage-gated proton channel, 1 voltage-independent cation channel, and 1 zinc activated ligand-gated ion channel (Additional file 1: Table S1).

\section{Gene expression data}

Eight independent microarray breast cancer datasets from Singapore (SIN) [15], France (FRA) [16], Germany
(GER) [34], Netherlands (NED) [21], Sweden (SWE) [18], Taiwan (TWN) [19], and the United States (USA1 and USA2) [20,27], were obtained for use in this study (Table 1). These datasets were chosen based on the large number of samples, the availability of clinical outcome data, and the diversity of tumor types. We assigned the SIN dataset as our discovery cohort and the other seven datasets as validation cohorts.

\section{Microarray data preprocessing}

The GC robust multichip average (GCRMA) algorithm [75] in Bioconductor was used to summarize the expression level of each probe set for the microarray data from our discovery cohort (Affymetrix Human Genome U133 set). Only the probe sets present (determined by function "mas5calls" in the Bioconductor "affy" package) in at least one third of the samples were retained. We further limited our analysis to the probe sets with unique annotations and removed genes on chromosomes $\mathrm{X}$ and $\mathrm{Y}$ to avoid the potential confounding sex factor.

\section{Statistical analysis}

For the SIN and FRA cohorts, a two-tailed $t$-test was used to identify the genes that were differentially expressed between p53 mutant and wild-type tumors. The genes with an adjusted $P$-value $<0.05$ after Benjamini \& Hochberg correction [22] and fold change $>$ 1.25 were deemed differentially expressed. The same methods and criteria were applied to identify the genes differentially expressed between ER positive and negative patients in SIN, FRA, USA1, and USA2 cohorts.

The Spearman's rank correlation test was used to detect the relationship between ion channel gene expression level and tumor histological grade. We calculated correlation coefficients and associated $P$-values using the $\mathrm{R}$ function "cor.test" with the "spearman" method. The genes with adjusted $P$-value $<0.05$ after Benjamini \& Hochberg correction were assigned as differentially expressed. We then tested the power of these tumor grade associated genes in predicting clinical outcome in breast cancers. Based on the relationship between gene expression and tumor grade, we can assign a Spearman's rank correlation coefficient to each gene as a weight (calculated solely from the discovery cohort). A risk score was then calculated for each patient using a linear combination of weighted gene expression as shown below:

$$
s=\sum_{i=1}^{n} \rho_{i}\left(e_{i}-\mu_{i}\right) / \tau_{i}
$$

Here, $s$ is the risk score of the patient; $n$ is the number of differentially expressed genes; $\rho_{i}$ denotes the Spearman's rank correlation coefficient of gene $i ; e_{i}$ 
denotes the expression level of gene $i$; and $\mu_{i}$ and $\tau_{i}$ are the mean and standard deviation of the gene expression values for gene $i$ across all samples, respectively. Patients were then divided into high-score (IC30 positive) and low-score (IC30 negative) groups with the median of the risk score as the threshold value. The median of the risk score was approximately equal to zero in each cohort (Additional file 2: Figure S5). A high score indicated a poor outcome. The "survival" library of the $\mathrm{R}$ was used to conduct survival analysis on the risk score.

Hierarchical cluster analysis was conducted to generate the gene expression heatmaps. The statistical significance of hierarchical cluster was evaluated by approximately unbiased $P$-value $(A U)$, which is computed by multiscale bootstrap resampling. $A U$ of a cluster is a value between 0 and 1 , which indicates how strong the cluster is supported by data. Higher $A U$ means lower uncertainty of the hierarchical cluster. The "pvclust" library of the $\mathrm{R}$ was used to compute the $A U$ values.

\section{Additional files}

Additional file 1: Table S1. Ion channel genes involved in this study. Table S2. Comparison in gene expression level between p53 mutant and wildtype tumors in validation cohorts. Table S3. Comparison in gene expression level between ER positive and negative tumors. Table S4. Correlation between gene expression and histological tumor grade. Table S5. Comparison in prognostic power between IC30 and clinicopathological factors for the USA1 cohort. Hazard ratio was calculated separately for each variable by univariate Cox proportional hazard regression of survival. Table S6. Comparison in prognostic power between IC30 and clinicopathological factors for the FRA cohort. Hazard ratio was calculated separately for each variable by univariate Cox proportional hazard regression of survival.

Additional file 2: Figure S1. Heatmaps of expression of the ion channel genes differentially expressed between ER positive and negative tumors. The differentially expressed genes were derived from the discovery cohort (SIN). Each row in the heatmaps was labelled with the corresponding gene symbol. The columns labelled with "-" denote ER positive tumors. Red represents relatively increased gene expression while blue represents down-regulation. Figure S2. Heatmaps of gene expression in FRA cohort. The listed genes are differentially expressed between ER positive and negative tumors in the discovery cohort (SIN). Each row in the heatmaps was labelled with the corresponding gene symbol. The columns labelled with "-" denote ER positive tumors. Red represents relatively increased gene expression while blue represents down-regulation. Figure S3. Heatmaps of gene expression in GER cohort. The listed genes are differentially expressed between ER positive and negative tumors in the discovery cohort (SIN). Each row in the heatmaps was labelled with the corresponding gene symbol. The columns labelled with "-" denote ER positive tumors. Red represents relatively increased gene expression while blue represents down-regulation. Figure $\mathbf{S 4}$. Heatmaps of gene expression in USA1 cohort. The listed genes are differentially expressed between ER positive and negative tumors in the discovery cohort (SIN). Each row in the heatmaps was labelled with the corresponding gene symbol. The columns labelled with "-" denote ER positive tumors. Red represents relatively increased gene expression while blue represents down-regulation. Figure S5. Distribution of risk score. The red dash lines indicate the median of risk score. There is no significant deviation between zero and the median of risk score in each cohort $(|z|<0.2)$.

\section{Abbreviations}

$\mathrm{K}^{+}$: Potassium ion; $\mathrm{Ca}^{2+}$ : Calcium ion; $\mathrm{Na}^{+}$: Sodium ion; $\mathrm{CL}^{-}$: Chloride ion $\mathrm{Kv}$ : Voltage-gated potassium channel; $\mathrm{K}_{\mathrm{Ca}}$ : Calcium-activated potassium channel; TRP: Transient receptor potential channel; NaV: Voltage-gated sodium channel; VDAC: Voltage-dependent anion channel; ER: Estrogen receptor; PR: Progesterone receptor; $\rho$ : Spearman's rank correlation coefficient; AU: Approximately unbiased P-value; IC30: Molecular signature consisting of 30 ion channel genes.

\section{Competing interests}

The authors declare that they have no competing interests.

\section{Authors' contributions}

JHK, EAK, WG, IL, HWB, and TZ designed the study; JHK, EAK, and TZ collected the data. JHK and TZ carried out analyses and prepared figures; HWB conceived of the study; JHK, EAK, WG, IL, HWB, and TZ wrote the manuscript. All authors read and approved the final manuscript.

\section{Acknowledgements}

This work was supported by the Korea Research Foundation Grant funded by the Korean Government (MOEHRD, Basic Research Promotion Fund) (KRF2011-0016587 to JHK).

\section{Author details}

'Department of Physiology, College of Medicine, Chung-Ang University, Seoul 156-756, South Korea. ${ }^{2}$ Department of Medicine, University of California-San Francisco, San Francisco, CA 94143, USA. ${ }^{3}$ Research Center for Learning Sciences, Southeast University, Nanjing, Jiangsu 210096, China. ${ }^{4}$ Institute for Personalized Respiratory Medicine, University of Illinois at Chicago, Chicago, IL 60612, USA. ${ }^{5}$ Department of Medicine, University of Illinois at Chicago, Chicago, IL 60612, USA.

Received: 11 April 2013 Accepted: 16 September 2013 Published: 22 September 2013

\section{References}

1. Verkman AS, Galietta L: Chloride channels as drug targets. Nat Rev Drug Discov 2009, 8:153-171.

2. Camerino DC, Tricarico D, Desaphy JF: Ion channel pharmacology. Neurotherapeutics 2007, 4:184-198.

3. Camerino DC, Desaphy JF, Tricarico D, Pierno S, Liantonio A: Therapeutic approaches to ion channel diseases. Adv Genet 2008, 64:81-145.

4. Hubner CA, Jentsch TJ: Ion channel diseases. Hum Mol Genet 2002, 11:2435-2445

5. Rebhan M, Chalifa-Caspi V, Prilusky J, Lancet D: GeneCards: a novel functional genomics compendium with automated data mining and query reformulation support. Bioinformatics 1998, 14:656-664.

6. Fiske JL, Fomin VP, Brown ML, Duncan RL, Sikes RA: Voltage-sensitive ion channels and cancer. Cancer Metastasis Rev 2006, 25:493-500.

7. Roger S, Potier M, Vandier C, Besson P, Le Guennec JY: Voltage-gated sodium channels: new targets in cancer therapy? Curr Pharm Des 2006, 12:3681-3695.

8. Jentsch TJ, Hubner CA, Fuhrmann JC: Ion channels: function unravelled by dysfunction. Nat Cell Biol 2004, 6:1039-1047.

9. Rebhan M, Chalifa-Caspi V, Prilusky J, Lancet D: GeneCards: integrating information about genes, proteins and diseases. Trends Genet 1997. 13:163.

10. Lehmann-Horn F, Jurkat-Rott K: Voltage-gated ion channels and hereditary disease. Physiol Rev 1999, 79:1317-1372.

11. Le Guennec JY, Ouadid-Ahidouch H, Soriani O, Besson P, Ahidouch A, Vandier C: Voltage-gated ion channels, new targets in anti-cancer research. Recent Pat Anticancer Drug Discov 2007, 2:189-202.

12. Pardo LA, Contreras-Jurado C, Zientkowska M, Alves F, Stuhmer W: Role of voltage-gated potassium channels in cancer. J Membr Biol 2005, 205:115-124.

13. Pardo LA, Stuhmer W: Eag1: an emerging oncological target. Cancer Res 2008, 68:1611-1613

14. Kunzelmann K: Ion channels and cancer. J Membr Biol 2005, 205:159-173.

15. Miller LD, Smeds J, George J, Vega VB, Vergara L, Ploner A, Pawitan Y, Hall P, Klaar S, Liu ET, Bergh J: An expression signature for p53 status in human 
breast cancer predicts mutation status, transcriptional effects, and patient survival. Proc Natl Acad Sci U S A 2005, 102:13550-13555.

16. Sabatier R, Finetti $P$, Adelaide J, Guille A, Borg JP, Chaffanet M, Lane L, Birnbaum D, Bertucci F: Down-regulation of ECRG4, a candidate tumor suppressor gene, in human breast cancer. PLoS One 2011, 6:e27656.

17. Li M, Xiong ZG: Ion channels as targets for cancer therapy. Int J Physiol Pathophysiol Pharmacol 2011, 3:156-166.

18. Pawitan Y, Bjohle J, Amler L, Borg AL, Egyhazi S, Hall P, Han X, Holmberg L, Huang F, Klaar S, et al: Gene expression profiling spares early breast cancer patients from adjuvant therapy: derived and validated in two population-based cohorts. Breast Cancer Res 2005, 7:R953-R964.

19. Kao KJ, Chang KM, Hsu HC, Huang AT: Correlation of microarray-based breast cancer molecular subtypes and clinical outcomes: implications for treatment optimization. BMC Cancer 2011, 11:143.

20. Wang Y, Klijn JG, Zhang Y, Sieuwerts AM, Look MP, Yang F, Talantov D, Timmermans M, Meijer-van Gelder ME, Yu J, et al: Gene-expression profiles to predict distant metastasis of lymph-node-negative primary breast cancer. Lancet 2005, 365:671-679.

21. van de Vijver MJ, He YD, van't Veer LJ, Dai H, Hart AA, Voskuil DW, Schreiber GJ, Peterse $J L$, Roberts C, Marton MJ, et al: A gene-expression signature as a predictor of survival in breast cancer. $N$ Engl J Med 2002, 347:1999-2009.

22. Benjamini $Y$, Hochberg $Y$ : Controlling the false discovery rate - a practical and powerful approach to multiple testing. J Roy Stat Soc B Met 1995, 57:289-300

23. Pharoah PD, Day NE, Caldas C: Somatic mutations in the p53 gene and prognosis in breast cancer: a meta-analysis. Br J Cancer 1999, 80:1968-1973.

24. Sontheimer $\mathrm{H}$ : An unexpected role for ion channels in brain tumor metastasis. Exp Biol Med (Maywood) 2008, 233:779-791.

25. Borresen-Dale AL: TP53 and breast cancer. Hum Mutat 2003, 21:292-300.

26. Sommer S, Fuqua SA: Estrogen receptor and breast cancer. Semin Cancer Biol 2001, 11:339-352.

27. Hatzis C, Pusztai L, Valero V, Booser DJ, Esserman L, Lluch A, Vidaurre T, Holmes F, Souchon E, Wang $H$, et al: A genomic predictor of response and survival following taxane-anthracycline chemotherapy for invasive breast cancer. JAMA 2011, 305:1873-1881.

28. Jemal A, Bray F, Center MM, Ferlay J, Ward E, Forman D: Global cancer statistics. CA Cancer J Clin 2011, 61:69-90.

29. Bertheau $P$, Espie M, Turpin E, Lehmann J, Plassa LF, Varna M, Janin A, de The H: TP53 status and response to chemotherapy in breast cancer Pathobiology 2008, 75:132-139.

30. Soussi T: p53 alterations in human cancer: more questions than answers. Oncogene 2007, 26:2145-2156.

31. Andersson J, Larsson L, Klaar S, Holmberg L, Nilsson J, Inganas M, Carlsson G, Ohd J, Rudenstam CM, Gustavsson B, Bergh J: Worse survival for TP53 (p53)-mutated breast cancer patients receiving adjuvant CMF. Ann Oncol 2005, 16:743-748.

32. Varna M, Bousquet $G$, Plassa LF, Bertheau P, Janin A: TP53 status and response to treatment in breast cancers. J Biomed Biotechnol 2011, 2011:284584.

33. Hensel M, Schneeweiss A, Sinn HP, Egerer G, Solomayer E, Haas R, Bastert G, Ho AD: P53 is the strongest predictor of survival in high-risk primary breast cancer patients undergoing high-dose chemotherapy with autologous blood stem cell support. Int J Cancer 2002, 100:290-296.

34. Schmidt M, Bohm D, von Torne C, Steiner E, Puhl A, Pilch H, Lehr HA, Hengstler JG, Kolbl H, Gehrmann M: The humoral immune system has a key prognostic impact in node-negative breast cancer. Cancer Res 2008, 68:5405-5413.

35. Troester MA, Herschkowitz JI, Oh DS, He X, Hoadley KA, Barbier CS, Perou $\mathrm{CM}$ : Gene expression patterns associated with $\mathrm{p} 53$ status in breast cancer. BMC Cancer 2006, 6:276.

36. Malamou-Mitsi V, Gogas H, Dafni U, Bourli A, Fillipidis T, Sotiropoulou M, Vlachodimitropoulos D, Papadopoulos S, Tzaida O, Kafiri G, et al: Evaluation of the prognostic and predictive value of p53 and $\mathrm{BCl}-2$ in breast cancer patients participating in a randomized study with dose-dense sequential adjuvant chemotherapy. Ann Oncol 2006, 17:1504-1511.

37. Sirvent JJ, Salvado MT, Santafe M, Martinez S, Brunet J, Alvaro T, Palacios J: p53 in breast cancer. Its relation to histological grade, lymph-node status, hormone receptors, cell-proliferation fraction (ki-67) and c-erbB-2.

Immunohistochemical study of 153 cases. Histol Histopathol 1995, 10:531-539.
38. Pitroda SP, Zhou T, Sweis RF, Filippo M, Labay E, Beckett MA, Mauceri HJ, Liang H, Darga TE, Perakis S, et al: Tumor endothelial inflammation predicts clinical outcome in diverse human cancers. PLoS One 2012, 7:e46104.

39. Finak G, Bertos N, Pepin F, Sadekova S, Souleimanova M, Zhao H, Chen $H$, Omeroglu G, Meterissian S, Omeroglu A, et al: Stromal gene expression predicts clinical outcome in breast cancer. Nat Med 2008, 14:518-527.

40. Navab R, Strumpf D, Bandarchi B, Zhu CQ, Pintilie M, Ramnarine VR, Ibrahimov E, Radulovich N, Leung L, Barczyk M, et al: Prognostic geneexpression signature of carcinoma-associated fibroblasts in non-small cell lung cancer. Proc Natl Acad Sci U S A 2011, 108:7160-7165.

41. Saadi A, Shannon NB, Lao-Sirieix P, O'Donovan M, Walker E, Clemons NJ, Hardwick JS, Zhang C, Das M, Save V, et al: Stromal genes discriminate preinvasive from invasive disease, predict outcome, and highlight inflammatory pathways in digestive cancers. Proc Natl Acad Sci U S A 2010, 107:2177-2182.

42. Lossos IS, Czerwinski DK, Alizadeh AA, Wechser MA, Tibshirani R, Botstein D, Levy R: Prediction of survival in diffuse large-B-cell lymphoma based on the expression of six genes. N Engl J Med 2004, 350:1828-1837.

43. Pedersen SF, Stock C: Ion channels and transporters in cancer: Pathophysiology, regulation and clinical potential. Cancer Res 2013, 73:1658-1661.

44. Prevarskaya N, Skryma R, Shuba Y: Ion channels and the hallmarks of cancer. Trends Mol Med 2010, 16:107-121.

45. Ouadid-Ahidouch $\mathrm{H}$, Ahidouch $\mathrm{A}$ : $\mathrm{K}+$ channel expression in human breast cancer cells: involvement in cell cycle regulation and carcinogenesis. J Membr Biol 2008, 221:1-6.

46. Wonderlin WF, Strobl JS: Potassium channels, proliferation and G1 progression. J Membr Biol 1996, 154:91-107

47. Hemmerlein B, Weseloh RM, Mello de Queiroz F, Knotgen H, Sanchez A, Rubio ME, Martin S, Schliephacke T, Jenke M, Heinz Joachim R, et al: Overexpression of Eag1 potassium channels in clinical tumours. Mol Cancer 2006, 5:41.

48. Stuhmer W, Alves F, Hartung F, Zientkowska M, Pardo LA: Potassium channels as tumour markers. FEBS Lett 2006, 580:2850-2852.

49. Mu D, Chen L, Zhang X, See LH, Koch CM, Yen C, Tong JJ, Spiegel L, Nguyen KC, Servoss A, et al: Genomic amplification and oncogenic properties of the KCNK9 potassium channel gene. Cancer Cell 2003, 3:297-302.

50. Stringer BK, Cooper AG, Shepard SB: Overexpression of the G-protein inwardly rectifying potassium channel 1 (GIRK1) in primary breast carcinomas correlates with axillary lymph node metastasis. Cancer Res 2001, 61:582-588.

51. Abdul M, Santo A, Hoosein N: Activity of potassium channel-blockers in breast cancer. Anticancer Res 2003, 23:3347-3351.

52. Haren N, Khorsi H, Faouzi M, Ahidouch A, Sevestre $H$, Ouadid-Ahidouch $H$ : Intermediate conductance $\mathrm{Ca} 2+$ activated $\mathrm{K}+$ channels are expressed and functional in breast adenocarcinomas: correlation with tumour grade and metastasis status. Histol Histopathol 2010, 25:1247-1255.

53. Khaitan D, Sankpal UT, Weksler B, Meister EA, Romero IA, Couraud PO, Ningaraj NS: Role of KCNMA1 gene in breast cancer invasion and metastasis to brain. BMC Cancer 2009, 9:258.

54. Suh KS, Malik M, Shukla A, Yuspa SH: CLIC4, skin homeostasis and cutaneous cancer: surprising connections. Mol Carcinog 2007, 46:599-604.

55. Walia $V$, Ding $M$, Kumar $S$, Nie D, Premkumar LS, Elble RC: hCLCA2 is a p53-inducible inhibitor of breast cancer cell proliferation. Cancer Res 2009, 69:6624-6632.

56. Gruber AD, Pauli BU: Tumorigenicity of human breast cancer is associated with loss of the Ca2+-activated chloride channel CLCA2. Cancer Res 1999, 59:5488-5491.

57. Jentsch TJ, Stein V, Weinreich F, Zdebik AA: Molecular structure and physiological function of chloride channels. Physiol Rev 2002, 82:503-568,

58. Wang XT, Nagaba Y, Cross HS, Wrba F, Zhang L, Guggino SE: The mRNA of L-type calcium channel elevated in colon cancer: protein distribution in normal and cancerous colon. Am J Pathol 2000, 157:1549-1562.

59. Oguro-Okano M, Griesmann GE, Wieben ED, Slaymaker SJ, Snutch TP, Lennon VA: Molecular diversity of neuronal-type calcium channels identified in small cell lung carcinoma. Mayo Clin Proc 1992, 67:1150-1159

60. Aydar E, Yeo S, Djamgoz M, Palmer C: Abnormal expression, localization and interaction of canonical transient receptor potential ion channels in 
human breast cancer cell lines and tissues: a potential target for breast cancer diagnosis and therapy. Cancer Cell Int 2009, 9:23.

61. Peters AA, Simpson PT, Bassett JJ, Lee JM, Da Silva L, Reid LE, Song S, Parat MO, Lakhani SR, Kenny PA, et al: Calcium channel TRPV6 as a potential therapeutic target in estrogen receptor-negative breast cancer. Mol Cancer Ther 2012, 11:2158-2168.

62. Lehen'kyi V, Raphael M, Prevarskaya N: The role of the TRPV6 channel in cancer. J Physiol 2012, 590:1369-1376.

63. Ouadid-Ahidouch H, Dhennin-Duthille I, Gautier M, Sevestre H, Ahidouch A: TRP channels: diagnostic markers and therapeutic targets for breast cancer? Trends Mol Med 2013, 19:117-124.

64. Ouadid-Ahidouch H, Dhennin-Duthille I, Gautier M, Sevestre H, Ahidouch A: TRP calcium channel and breast cancer: expression, role and correlation with clinical parameters. Bull Cancer 2012, 99:655-664.

65. Fraser SP, Diss JK, Chioni AM, Mycielska ME, Pan H, Yamaci RF, Pani F, Siwy Z, Krasowska M, Grzywna Z, et al: Voltage-gated sodium channel expression and potentiation of human breast cancer metastasis. Clin Cancer Res 2005, 11:5381-5389.

66. Brisson L, Gillet L, Calaghan S, Besson P, Le Guennec JY, Roger S, Gore J: Na (V)1.5 enhances breast cancer cell invasiveness by increasing NHE1dependent $\mathrm{H}(+)$ efflux in caveolae. Oncogene 2011, 30:2070-2076.

67. Diss JK, Stewart D, Pani F, Foster CS, Walker MM, Patel A, Djamgoz MB: A potential novel marker for human prostate cancer: voltage-gated sodium channel expression in vivo. Prostate Cancer Prostatic Dis 2005, 8:266-273.

68. Arcangeli A, Crociani O, Lastraioli E, Masi A, Pillozzi S, Becchetti A: Targeting ion channels in cancer: a novel frontier in antineoplastic therapy. Curr Med Chem 2009, 16:66-93.

69. Gillet L, Roger S, Besson P, Lecaille F, Gore J, Bougnoux P, Lalmanach G, Le Guennec JY: Voltage-gated sodium channel activity promotes cysteine cathepsin-dependent invasiveness and colony growth of human cancer cells. J Biol Chem 2009, 284:8680-8691.

70. Diss JK, Fraser SP, Djamgoz MB: Voltage-gated Na+ channels: multiplicity of expression, plasticity, functional implications and pathophysiological aspects. Eur Biophys J 2004, 33:180-193.

71. Maier T, Schmidt A, Guell M, Kuhner S, Gavin AC, Aebersold R, Serrano L: Quantification of mRNA and protein and integration with protein turnover in a bacterium. Mol Syst Biol 2011, 7:511.

72. Goncalves RP, Buzhynskyy N, Prima V, Sturgis JN, Scheuring S: Supramolecular assembly of VDAC in native mitochondrial outer membranes. J Mol Biol 2007, 369:413-418.

73. Grills C, Jithesh PV, Blayney J, Zhang SD, Fennell DA: Gene expression meta-analysis identifies VDAC1 as a predictor of poor outcome in early stage non-small cell lung cancer. PLoS One 2011, 6:e14635.

74. Sharman JL, Mpamhanga CP, Spedding M, Germain P, Staels B, Dacquet C, Laudet $V$, Harmar AJ: IUPHAR-DB: new receptors and tools for easy searching and visualization of pharmacological data. Nucleic Acids Res 2011, 39:D534-D538.

75. Wu Z, Irizarry RA, Gentleman R, Martinez-Murillo F, Spencer F: A modelbased background adjustment for oligonucleotide expression arrays. J Am Stat Assoc 2004, 99:909-917.

doi:10.1186/1476-4598-12-106

Cite this article as: Ko et al:: Expression profiling of ion channel genes predicts clinical outcome in breast cancer. Molecular Cancer 2013 12:106.

\section{Submit your next manuscript to BioMed Central and take full advantage of:}

- Convenient online submission

- Thorough peer review

- No space constraints or color figure charges

- Immediate publication on acceptance

- Inclusion in PubMed, CAS, Scopus and Google Scholar

- Research which is freely available for redistribution

Submit your manuscript at www.biomedcentral.com/submit
( Biomed Central 